\title{
Salivary Her2/neu Levels in Differentiation of Oral Premalignant Disorders and Oral Squamous Cell Carcinomas
}

\author{
Chopra Varun ${ }^{1}$, Thayalan Dineshkumar ${ }^{2}$, VS Jayant ${ }^{2}$,Annasamy Rameshkumar ${ }^{2}$, \\ Krishnan Rajkumar ${ }^{2}$, Padmanaban Rajashree ${ }^{3 *}$, Jacob Mathew ${ }^{4}$, Rajendran K \\ Arunvignesh ${ }^{2}$
}

\begin{abstract}
Background: Oral squamous cell carcinoma (OSCC) is thought to develop from precancerous dysplastic lesions through multistep processes of carcinogenesis involving activation of oncogenes and loss of tumor suppressor genes. The human epidermal growth factor receptor 2 (Her-2/neu [erbB-2]), a cell membrane glycoprotein, is a growth factor receptor that has receptor tyrosine kinase activity. Her $2 /$ neu activation plays a central role in cell proliferation and survival. It has been shown that overexpression of Her $2 / n e u$ increases the rate of cell division and growth, leading to precancerous changes. The aim of the present study was to compare the serum and salivary Her2/neu levels between cases with premalignant and malignant oral lesions. Materials and Methods: Fasting blood samples and unstimulated saliva by passive drooling were collected from three groups of healthy control $(n=20)$, premalignant disorder $(P M D)(n=20)$ and OSCC $(n=25)$ subjects. The HER2 extracellular domain (HER2 ECD) levels were measured using ELISA. Results: The levels of serum Her2/neu showed no significant differences between any of the groups but on the other hand salivary Her2/neu levels were found to be significantly $(\mathbf{p}<0.05)$ higher when compared between control (median $68.7 \mathrm{pg} / \mathrm{ml}$, range: 21.5 - 75.8) and OSCC (median 145.6 pg/ml, range: 45.1-191.1). A similar trend was observed when comparing between PMD (median 43.3, range: $22.1-94.7$ ) and OSCC with a statistical significance of $\mathbf{p}<0.05$. Conclusions: Our study provided evidence of increased salivary Her2/neu in OSCC when compared to PMD and control which was not the case for serum levels. This suggests that probably Her2/neu is not highly amplified as in breast cancer so as to be reflected in serum. Since saliva is in local vicinity of the OSCC, even a mild increase might be mirrored. On the whole, this study proposes Her2/neu as marker for distinguishing premalignant and malignant conditions.
\end{abstract}

Keywords: Her2/neu ECD level - oral SCC - premalignant disorder - differentiaion

Asian Pac J Cancer Prev, 16 (14), 5773-5777

\section{Introduction}

One of the most common malignancies in India is oral squamous cell carcinoma (OSCC), whose incidence is ever increasing (specifically in younger people). The 5 -year mortality rate of $50 \%$ has not changed significantly in past few decades for OSCC (Ferlay et al., 2010). It is important to note that though there are lot of advancements in treatment, still the diagnostic procedure depends on histopathological investigation which is time consuming and a laborious process. Hence thorough understanding of molecular changes occurring in OSCC has to be achieved for designing better diagnostics and therapeutics (Tsantoulis et al., 2007).

OSCC is thought to develop from precancerous dysplastic lesions through multistep processes of carcinogenesis involving activation of oncogenes and loss of tumor suppressor genes. Similar to OSCC, the incidence of premalignant disorder (PMD) of the oral cavity such as oral leukoplakia and oral submucous fibrosis is also very high in India, particularly in South India. The reason of this high incidence is not fully known and is attributed to several factors such as chewing, smoking and viral infections. Whatever may be the causative factor, very little information is available on the molecular derangements leading to the transition of a precancerous lesion to malignancy (Mithani et al., 2007). Therefore, identifying carcinomal abnormalities in OSCCs might provide an important tool for disease detection and contribute to the future development of tailored treatments based on the presence of specific markers.

Of late, there has been an ever-growing effort dedicated to the basic research of oral cancer, focusing on the identification of biological indicators and transforming

${ }^{1}$ Oral and Maxillofacial Pathology, Indian Ocean Dental School and Hospital, Arsenal, Republic of Mauritius, ${ }^{2}$ Oral and Maxillofacial Pathology, ${ }^{3}$ Research Faculty, SRM Dental College, Ramapuram, Chennai, ${ }^{4}$ Department of Oral and Maxillofacial Pathology, Vinayaka Mission’s Sankarachariyar Dental College, Salem, India ¿Equal contributors *For correspondence: drprajashree@ gmail.com 
mechanisms. It is well documented that signal transduction pathways by growth factor and its receptor play an important role in the carcinogenic process. The human epidermal growth factor receptor 2 (Her-2/neu [erbB-2]) protein, cell membrane glycoprotein, is a growth factor receptor that has the activity of receptor tyrosine kinase. Her2/neu activation plays a central role in cell proliferation and survival, largely mediated through the RAS-MAP Kinase pathway (Citri et al., 2006). It also inhibits cell death through the phosphatidylinositol 3'-kinase-AKTmammalian target of rapamycin (mTOR) pathway. High Her2/neu expression has been frequently detected in a wide variety of human tumors like breast cancer, osteosarcoma, ovarian cancer and also in oral cancer and other head neck cancer. It's been shown that over expression of Her2/neu increases the rate of cell division and growth leading to precancerous changes (Cross et al., 1991). Furthermore, detection of HER in saliva of OSCC subjects has also been reported, however, their production in oral premalignant conditions has not been investigated. However, not much is known about the status of Her2/neu in PMD condition. Moreover, very few studies have analysed the serum and salivary Her2/neu level in OSCC, most of the studies have evaluated Her2/neu gene amplification or its expression in tumor tissue. Therefore, this study was planned to assess the serum and salivary Her2/neu levels between premalignant and malignant oral lesions. The potential value of findings would be to offer a basis for predicting the malignant transformation of a premalignant lesion (e.g., leukoplakia or erythroplakia).

\section{Materials and Methods}

\section{Study subject recruitment}

The study protocol was approved by the institutional review board for biomedical research and followed the guidelines. Before entry to the study, all patients were required to sign a consent form and clinical history was recorded. Study subjects were recruited from the outpatient department of SRM Dental College, Chennai. The study comprised of three groups namely Control healthy subjects $(n=20)$, premalignant disorder (PMD) subjects $(n=20)$ and OSCC subjects $(n=25)$. Subjects with infectious diseases during one month before saliva sampling, active dental abscesses, systemic illness and collagen vascular diseases were excluded from the study. None of the control participants had oral lesions. None of the lesions (in precancer and OSCC group) had been treated in any manner prior to sample collection. Pregnant and lactating subjects were also excluded. After registering the eligible patients, the histopathologic examination was carried out for premalignant and OSCC subjects. A standard tissue biopsy was taken from each patient. The diagnosis was confirmed by two pathologists independently. The biopsies were further classified based on histopathological gradation.

\section{Blood and salivary sample collection}

Fasting blood samples were collected from all patients and control groups. This blood was left to clot for 20-30 min at room temperature, followed by centrifugation at
$1500 \mathrm{~g}$ for $10 \mathrm{~min}$. The serum was then transferred to a polypropylene tube and stored at $-80^{\circ} \mathrm{C}$ until use.

For saliva collection all study subjects were asked not to eat, drink, or smoke for at least 2 hours before the test. Each patient was required to rinse the mouth at least thrice and to sit for 5 minutes before collection. Unstimulated saliva was collected by passive drooling. Minimum of $5 \mathrm{~mL}$ of saliva was collected in a plastic cup. The saliva samples were centrifuged at 2,000 rpm for 10 minutes; the supernatant was then stored at $-80^{\circ} \mathrm{C}$ for later analysis

\section{Measurement of Serum and salivary HER2/neu}

The HER2 ECD levels were measured using ELISA (eBioscience human sHER-2 platinum ELISA kit, San Diego, California, USA.), following the manufacturer's recommended protocol. The concentration of Her2/neu in the samples was determined by interpolation of the sample absorbance from the standard curve. The minimum detectable was $0.06 \mathrm{ng} / \mathrm{mL}$. The results were expressed as $\mathrm{pg} / \mathrm{ml}$.

\section{Statistical analysis}

For descriptive statistics, the frequency and percentage were calculated for qualitative variables, the mean values \pm standard deviation (SD) were used for quantitative variables. For comparison between groups One way ANOVA followed by post-hoc test was used. Statistical computations were done on a personal computer using the
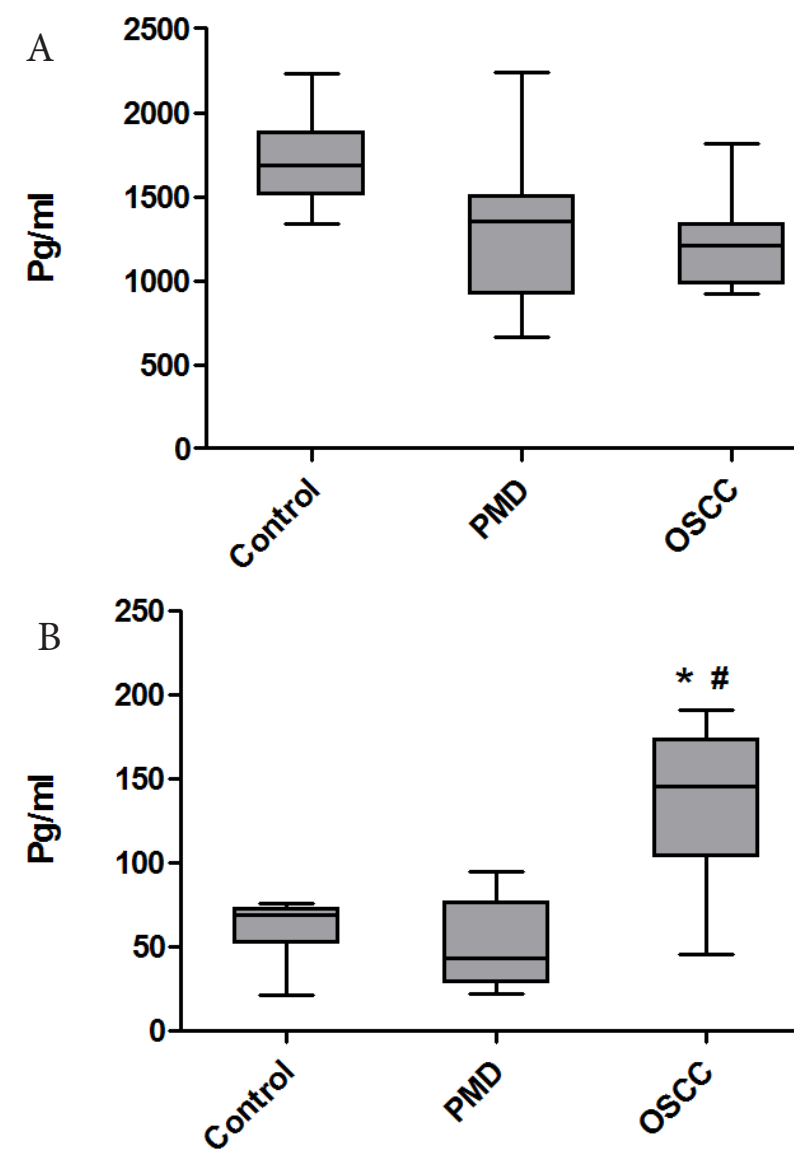

Figure 1. Serum and salivary levels of Her2/neu in healthy control, OSCC and PML subjects 
computer software SPSS version 20 (Chicago, IL, USA). Univariate correlation was used to study the association between Her2/neu level and clinical parameters. All p-values were two-sided and a p-value of less than 0.05 was considered to indicate a statistically significant difference.

\section{Results}

\section{Study subjects characteristics}

The main features of study subjects in the three groups are summarized in Table 1. The analysis of patients with PMD and OSCC revealed a male predominance $(60 \%)$ and a mean age of $43.6 \pm 3.5$. All the PMD and OSCC subjects either had tobacco/pan chewing/smoking or alcohol intake habits. Details concerning clinical and microscopic findings are also summarized in Table 1. The site of lesion in PMD and OSCC was mostly observed in buccal mucosa. Histologically, majority of the OSCC lesions were found to be well differentiated. Similarly, most of the patients in OSCC were under stage I of TNM classification.
Serum and salivary Her2/neu levels

The serum and salivary levels of Her2/neu in healthy control OSCC and PML subjects are shown in Figure $1 \mathrm{~A}$ and $\mathrm{B}$, respectively. The levels of serum Her2/neu showed no significant difference between any of the group. However, control serum showed higher levels (median 1681.5, range: $1338-2230 \mathrm{pg} / \mathrm{ml}$ ) than OSCC (median $1354 \mathrm{pg} / \mathrm{ml}$, range: $6612238 \mathrm{pg} / \mathrm{ml}$ ). On the other hand Salivary Her2/neu levels was found to be significantly $(\mathrm{p}<0.05)$ higher when compared between control (median $68.7 \mathrm{pg} / \mathrm{ml}$, range: 21.5 - 75.8) and OSCC (median 145.6 pg/ml, range: 45.1-191.1). Similar trend was observed when compared between PMD (median 43.3, range: 22.1 -94.7) and OSCC with a statistical significance of $\mathrm{p}<0.05$ (Figure 1B).

\section{Comparison of serum and salivary Her2/neu level}

The mean \pm SEM values for Her2/neu levels in serum and saliva is summarized in Table 2 . As expected, the serum Her2/neu levels were higher (atleast 10 fold) than salivary Her2/neu levels in all the groups. Though serum levels were higher it was not statistically significant

Table 1. Demographics and Clinical Characteristics of Study Groups

\begin{tabular}{|c|c|c|c|c|}
\hline \multirow[b]{2}{*}{ Category } & \multirow[b]{2}{*}{ Control } & \multicolumn{2}{|c|}{ PMD group } & \multirow[b]{2}{*}{ OSCC } \\
\hline & & Leukoplakia & OSMF & \\
\hline Subjects (n) & 20 & 10 & 10 & 25 \\
\hline Age range (years) & $25-50$ & $21-60$ & $21-60$ & $25-65$ \\
\hline \multicolumn{5}{|l|}{ Sex: } \\
\hline Male & $10(50 \%)$ & $6(60 \%)$ & $7(70 \%)$ & $17(68 \%)$ \\
\hline Female & $10(50 \%)$ & $4(40 \%)$ & $3(30 \%)$ & $8(32 \%)$ \\
\hline \multicolumn{5}{|l|}{ Habits: } \\
\hline Tobacco chewing & - & $5(50 \%)$ & $8(80 \%)$ & $6(24 \%)$ \\
\hline Smoking & - & $2(20 \%)$ & - & $5(20 \%)$ \\
\hline Smoking \& chewing & - & $1(10 \%)$ & $2(20 \%)$ & $7(28 \%)$ \\
\hline Smoking \& alcohol & - & $1(10 \%)$ & - & $4(16 \%)$ \\
\hline Alcohol only & - & $1(10 \%)$ & - & $3(12 \%)$ \\
\hline \multicolumn{5}{|l|}{ Site of Lesion } \\
\hline Buccal mucosa & - & $6(60 \%)$ & $7(70 \%)$ & $18(72 \%)$ \\
\hline Buccal mucosa \& Vestibule & - & $4(40 \%)$ & $3(30 \%)$ & - \\
\hline Tongue & - & - & - & $5(20 \%)$ \\
\hline Lip & - & - & - & $2(8 \%)$ \\
\hline \multicolumn{5}{|l|}{ Histological differentiation of OSCC } \\
\hline Well differentiated (WD) & - & - & - & $11(44 \%)$ \\
\hline Moderately differentiated (MD) & - & - & - & $7(28 \%)$ \\
\hline Poorly differentiated (PD) & - & - & - & $7(28 \%)$ \\
\hline TNM Staging of OSCC patients & - & - & - & \\
\hline Stage I & - & - & - & $11(44 \%)$ \\
\hline Stage II & - & - & - & $10(40 \%)$ \\
\hline Stage III & - & - & - & $4(16 \%)$ \\
\hline
\end{tabular}

Table 2. Comparison of Her2/neu levels in Serum and Saliva

\begin{tabular}{lccc}
\hline Study Subjects & $\mathrm{n}$ & Serum Her2/neu & Salivary Her2/neu \\
\hline Healthy Control & 20 & $1710.2 \pm 260.4$ & $61.4 \pm 17 \$$ \\
Premalignant Disorder & 20 & $1316.3 \pm 453.8$ & $50.60 \pm 24.4 \$$ \\
Oral squamous cell carcinoma & 25 & $1209.2 \pm 271.4$ & $135.9 \pm 45.9 * \$ \$$ \\
\hline
\end{tabular}

*The levels of serum and salivary Her2/neu were assessed by ELISA in all the study subjects. The concentrations are expressed in picogram per millilitre, and the values represent mean \pm SEM. $* \mathrm{p}<0.05$ when compared with healthy control group, ${ }^{\#}$ when compared to premalignant lesion group and $\$$ when compared between serum and saliva 
between groups. To assess whether serum and salivary Her2/neu level are correlated, Pearson correlation analysis was carried out, but there was no correlation observed. Similarly, a univariate correlation analysis was performed to study the association of clinicopathologic factor with serum and salivary Her2/neu levels. The analysis revealed no association with any parameter. There was no significant correlation observed between any of the clinicopathologic factors and Her2/neu level in serum and saliva (data not shown).

\section{Discussion}

Arrest of cell growth and apoptosis are considered powerful tumour suppressor mechanisms through their control of the proliferative potential of cells. This mechanism is shown to be curbed by one of the cell signalling molecule Her2/neu. Cell survival is shown to be enhanced by Her2/neu protein, in turn promoting carcinogenesis. The role of Her $2 /$ neu as a monitoring marker in breast cancer has been well established. Various studies have been published on expression of Her2/neu in oral cancer, but few studies are available for salivary Her2/neu level and to the best of our knowledge, no data are available on oral premalignant disorder/ lesions. The study of Her2/neu in oral premalignant lesions is of particular relevance due to the potential of applying preventive measures and also in understanding the role of this molecule in the carcinogenesis of oral neoplasms. The present study revealed that significantly higher level of salivary Her2/neu in OSCC when compared with control and PMD group.

Her2/neu is an oncoprotein, which belongs to the EGFR family and plays a major role in proliferation, cell growth and differentiation. Binding of specific ligands to the extracellular domain of Her2/neu forms heterodimers and that way initiates cell signaling, resulting in inhibition of apoptosis and activation of tumor cell growth and invasion. The amplification of Her2/neu gene was first reported almost 30 years back in breast cancer. Since then, Her2/neu amplification and resultant Her2/neu protein over expression have been demonstrated in many tumor types; several drugs have been developed to target the pathway. Despite the receptor's clinical importance for breast cancer, the role of Her2/neu in OSCC is still controversial.

Over expression of Her2/neu gene amplification was initially identified in OSCC cell line by Tadokoro et al. (1989). Supporting this various studies reported over expression and aberrant mutation of Her2/neu in OSSC tissues. This scenario was also observed and reported in oral dysplastic premalignant disorder (Hou et al., 1992). Thus, it was suggested as a marker for oral cancer (Li et al., 1992; Xia et al., 1997; Werkmeister et al., 1999; Fong et al., 2008) and also as a prognostic marker (Pinto et al., 2010; Stoicanescu et al., 2013) for monitoring disease progression. However, there is also evidence stating that low/absence of HER2/neu expression in oral cancer (Khan et al., 2002; Schartinger et al., 2004; Henning Hanken et al., 2014). Henning et al demonstrated that Her2 protein and gene amplification was only detectable in a small subset of squamous cell carcinomas of the head and neck region as well as oral squamous cell carcinomas. However, speculated that those few patients with Her2 overexpressing and gene amplified tumors may possibly benefit from an anti-Her2 therapy (Henning et al., 2014).

Lutfiye Demir studied the expression of HER2/neu and EGFR expression in ovarian carcinoma and pointed out that HER2 positivity significantly shortens overall survival times in patients with advanced-stage disease, and the HER2 positive phenotype has more aggressive behavior compared with the negative phenotype and EGFR expression is more frequent in advanced tumors (Lutfiye et al., 2014).

With regard to the serum Her2/neu level in OSCC, few studies has analysed and showed that Her2/neu level to be elevated (Chen et al., 2004; Chen et al., 2007) contrastingly the present study did not show such observation. In fact all the three groups had almost similar levels of serum Her2/neu. The probable reason behind this may be because majority of the OSCC patients were from stage I, which corroborates with previous report suggesting that Her2/neu expression was higher only in late stage or during metastasis (Ibrahim et al., 1999).

Salivary Her2/neu level in OSCC was found to be significantly higher than PMD and healthy control group which is in contrast to a study by Vanessa Bernandes et al. (2010) where they found no significant difference between OSCC and control subjects. This might be due to various factors like difference in the type of ELISA kit used, genetic makeup of study subjects and importantly in their study most of the OSSC lesion was from tongue region while in the present study more than $70 \%$ of OSCC lesion was from buccal mucosa. Difference in location of tumor lesion may have different pathogenic mechanism and hence might be reflected in Her2/neu level, yet, further investigations are required to prove this. Furthermore, there was no correlation of either serum or salivary Her2/neu level with clinicopathologic factors which is in concordance with many other studies (Safoura Seifi et al., 2009).

Immunohistochemical studies of Her2/neu expression in oral PMD lesion have reported mild expression (Safoura Seifi et al., 2009), furthermore, another study showed that it's expression was found only in dysplastic lesion. In concordance with this we also found no difference in the levels of salivary Her2/neu between PMD and control group. Moreover, it also suggests that Her2/neu may not be involved in PMD pathogenesis but rather in the transition of PMD to malignant condition. Further follow up studies in PMD subject is necessary to evaluate the role of Her2/ neu in PMD transition to cancerous condition.

In conclusion, the present study evidenced an increased salivary Her2/neu in OSCC when compared to PMD and control which was not the case in serum. This suggests that probably Her2/neu is not highly amplified as in breast cancer so as to be reflected in serum. Since, saliva is in local vicinity of the OSCC, even a mild increase is mirrored in it. On the whole, the study proposes Her $2 /$ neu as a marker for distinguishing premalignant and malignant condition. As small size is a limiting factor of this study, the above fact has to be proved with large sample size. 


\section{Acknowledgements}

The authors thank the Patients and healthy volunteers in the study for their willingness to contribute towards this study.

\section{References}

Chen CH, Lin YS, Lin CC, et al (2004). Elevated serum levels of a c-erbB-2 oncogene product in oral squamous cell carcinoma patients. J Oral Pathol Med, 33, 89-94.

Chen CH, Tsai TL, Yang YS, Tsai CC (2007). Studies of the serum HER-2/neu and squamous cell carcinoma-related antigen expression in patients with oral squamous cell carcinoma. J Oral Pathol Med, 36, 83-7.

Citri A, Yarden Y (2006). EGF-ERBB signalling: towards the systems level. Nat Rev Mol Cell Biol, 7, 505-16.

Cross M, Dexter TM (1991). Growth factors in development, transformation, and tumorigenesis. Cell, 64, 271-80.

Ferlay J, Shin HR, Bray F, et al (2010). Estimates of worldwide burden of cancer in 2008: Globocan 2008. Int J Cancer, 127, 2893-917.

Fong Y, Chou SJ, Hung KF, Wu HT, Kao SY (2008). An investigation of the differential expression of Her2/neu gene expression in normal oral mucosa, epithelial dysplasia, and oral squamous cell carcinoma in Taiwan. J Chin Med Assoc, 71, 123-27.

Henning H, Robert G, Alexander G, et al (2014). Her2 expression and gene amplification is rarely detectable in patients with oral squamous cell carcinomas. J Oral Pathol Med, 43, 304-8.

Hou L, Shi D, Tu SM, et al (1992). Oral cancer progression and c-erbB-2/neu proto-oncogene expression. Cancer Lett, 65, 215-20.

Ibrahim SO, Lillehaug JR, Johannessen AC, et al (1999). Expression of biomarkers (p53, transforming growth factor alpha, epidermal growth factor receptor, c-erbB-2/neu and the proliferative cell nuclear antigen) in oropharyngeal squamous cell carcinomas. Oral Oncol, 35, 302-13.

Khan AJ, King BL, Smith BD, et al (2002). Characterization of the HER-2/neu oncogene by immunohistochemical and fluorescence in situ hybridization analysis in oral and oropharyngeal squamous cell carcinoma. Clin Cancer Res, 8, 540-8.

Li B, Wang M, Wen Y, Chen J (1992). Erb-B oncogene in human oral squamous cell carcinomas. Hua Xi Yi Ke Da Xue Xиe Bao, 23, 284-87.

Lutfiye D, Seyran Y, Canan S, et al (2014). Hormone Receptor, HER2/NEU and EGFR Expression in Ovarian Carcinoma - is here a Prognostic Phenotype? Asian Pac J Cancer Prev, 15, 9739-45.

Mithani SK, Mydlarz WK, Grumbine FL, Smith IM, Califano JA (2007). Molecular genetics of premalignant oral lesions. Oral Dis, 13, 126-33.

Pinto LS, de Aguiar FC Jr, Kowalski LP, Graner E, Lopes MA (2010). FAS and ErbB2 expression in early local recurrent oral cancer. J Oral Pathol Med, 39, 176-81.

Safoura S, Shahriar S, Kamran N, Behzad A (2009). Lack of Elevated HER2/neu Expression in Epithelial Dysplasia and Oral Squamous Cell Carcinoma in Iran. Asian Pacific J Cancer Prev, 10, 661-4.

Schartinger VH, Kacani L, Andrle J, et al (2004). Pharmacodiagnostic value of the HER family in head and neck squamous cell carcinoma. ORL J Otorhinolaryngol Relat Spec, 66, 21-6.

Stoicanescu D, Andreescu N, Belengeanu A, Meszaros N, Cornianu M (2013). Assessment of p53 and HER-2/neu genes status and protein products in oral squamous cell carcinomas. Rom J Morphol Embryol, 54, 1107-13.

Tadokoro K, Ueda M, Ohshima T, et al (1989). Activation of oncogenes in human oral cancer cells: a novel codon 13 mutation of c-H-ras-1 and concurrent amplifications of c-erbB-1 and c-myc. Oncogene, 4, 499-505.

Tsantoulis PK, Kastrinakis NG, Tourvas AD, Laskaris G, Gorgoulis VG (2007). Advances in the biology of oral cancer. Oral Oncol, 43, 523-34.

Vanessa FB, Frederico O, Silvia FS, et al (2010). Clinical significance of EGFR, Her-2 and EGF in oral squamous cell carcinoma: a case control study. J Exp Clin Cancer Res, 29, 40.

Werkmeister R, Brandt B, Joos U (1999). Aberrations of erbB-1 and erbB-2 oncogenes in non-dysplastic leukoplakias of the oral cavity. Br J Oral Maxillofac Surg, 37, 477-80.

Xia W, Lau YK, Zhang HZ, et al (1997). Strong correlation between c-erbB-2 overexpression and overall survival of patients with oral squamous cell carcinoma. Clin Cancer Res, 3, 3-9. 